\title{
Comparison of dexmedetomidine and dexamethasone for prevention of postoperative nausea and vomiting after laparoscopic cholecystectomy
}

\author{
Mohamed H. Bakri ${ }^{1}$, Eman A. Ismail ${ }^{1}$, and Ahmed Ibrahim ${ }^{2}$ \\ ${ }^{1}$ Department of Anesthesia, Faculty of Medicine, Assiut University, Egypt, ${ }^{2}$ Department of Community Medicine, \\ Faculty of Medicine, University of Western Kordofan, Sudan
}

Background: Postoperative nausea and vomiting (PONV) are common following laparoscopic cholecystectomy (LC). Dexamethasone has been reported to reduce PONV. However, there is insufficient evidence regarding the effect of dexmedetomidine in decreasing PONV. This study was designed to compare the effects of a single dose of dexmedetomidine to dexamethasone for reducing PONV after LC.

Methods: Eighty-six adult patients scheduled for LC were randomized to receive either single dose $1 \mu \mathrm{g} / \mathrm{kg}$ of dexmedetomidine (Dexmed group, $\mathrm{N}=43$ ) or $8 \mathrm{mg}$ dexamethasone (Dexa group, $\mathrm{N}=43$ ) before skin incision. During the first $24 \mathrm{~h}$ postoperatively, the incidence and severity of PONV were assessed. Pain and sedation scores were assessed on arrival in the recovery room and early postoperatively. Analgesic and antiemetic consumption during the $24 \mathrm{~h}$ after surgery were calculated. Intra-operative and postoperative hemodynamics were recorded.

Results: Twenty-one percent of the patients in the Dexmed group developed PONV compared to 28\% in the Dexa group $(P=0.6)$. Severity of PONV was similar between the two groups $(P=0.07)$. Early postoperatively, pain severity was significantly lower in the Dexmed group, but sedation scores were significantly higher. The first analgesic request was significantly delayed in the Dexmed group $(\mathrm{P}=0.02)$. The total amounts of intraoperative fentanyl and postoperative tramadol administered were significantly lower in the Dexmed group. No difference in ondansetron was noted between the two groups. Mean arterial pressure and heart rate were significantly lower in the Dexmed group after administration of dexmedetomidine. No major side effects were reported.

Conclusions: Dexmedetomidine reduces the incidence and severity of PONV, similar to dexamethasone. It is superior to dexamethasone in reducing postoperative pain and total analgesic consumption during the first $24 \mathrm{~h}$ after LC.

Key Words: Cholecystectomy, Dexamethasone, Dexmedetomidine, Laparoscopy, Postoperative nausea and vomiting.

Corresponding author: Mohamed H. Bakri, M.D., Ph.D.

Department of Anesthesia, Faculty of Medicine, Assiut University, Assiut 71515, Egypt

Tel: 05030664463, Fax: 0135755150

E-mail:mhbakri@gmail.com

Received: November 24, 2014.

Revised: December 17, 2014.

Accepted: January 2, 2015.

Korean J Anesthesiol 2015 June 68(3): 254-260

http://dx.doi.org/10.4097/kjae.2015.68.3.254

\section{Introduction}

Postoperative nausea and vomiting (PONV) are usually defined as any nausea, retching, or vomiting that occurs during the first 24 postoperative hours [1]. PONV is one of the most common causes of patient dissatisfaction after anesthesia, with a reported incidence as high as $63 \%$ after laparoscopic cholecystectomy [2]. PONV may delay patient discharge from the postanesthesia care unit (PACU) and increase unanticipated hospital admissions in outpatients. Therefore, prevention of PONV will

(c) This is an open-access article distributed under the terms of the Creative Commons Attribution Non-Commercial License (http://creativecommons.org/ licenses/by-nc/4.0/), which permits unrestricted non-commercial use, distribution, and reproduction in any medium, provided the original work is properly cited. 
improve patient satisfaction and decrease overall health care costs.

Dexmedetomidine is a potent $\alpha_{2}$-adrenergic agonist with potential applications in clinical anesthesia because of its broadspectrum effects, which include anxiolytic, sedative, analgesic, anesthetic-sparing, sympatholytic, and hemodynamic-stabilizing properties [3]. The intra-operative use of dexmedetomidine as an anesthetic adjuvant has led to significant reductions in the use of opioids and inhalation anesthetics, reduction in the incidence of emergence agitation, a favorable recovery profile, and reduction of postoperative pain without adverse hemodynamic effects, and hence it may decrease PONV [3].

A pre-induction single dose of dexmedetomidine of 0.6-2 $\mu \mathrm{g} / \mathrm{kg}$ resulted in the reduction of both inhalational anesthetic and opioid analgesic requirements during the intra-operative period $[4,5]$. We chose the $1 \mu \mathrm{g} / \mathrm{kg}$ dose to avoid the hypotension and bradycardia that occurred with $2 \mu \mathrm{g} / \mathrm{kg}$ [5]. The aim of the study was to compare the effect of a single dose of $1 \mu \mathrm{g} / \mathrm{kg}$ of dexmedetomidine to a single dose of $8 \mathrm{mg}$ dexamethasone, after induction of anesthesia, on the incidence of PONV in patients undergoing laparoscopic cholecystectomy. Assessment of postoperative pain and calculations of total analgesic and antiemetic requirements during the first $24 \mathrm{~h}$ postoperatively were also recorded.

\section{Materials and Methods}

This was a randomized, controlled, double-blind study conducted with the approval of the Institutional Review Board and after receiving written informed consent from each participant. Over a period of 10 months, 86 adult patients scheduled for elective laparoscopic cholecystectomy agreed to participate in the study. Inclusion criteria included adult patients with American Society of Anesthesiologists (ASA) physical status I-II undergoing laparoscopic cholecystectomy for chronic calcular cholecystitis. Exclusion criteria included allergy to study medications, receiving antiemetic medication during the last $48 \mathrm{~h}$ before surgery, and body mass index above $35 \mathrm{~kg} / \mathrm{m}^{2}$. Patients were randomly allocated to receive an intravenous (IV) single dose of either $1 \mu \mathrm{g} / \mathrm{kg}$ of dexmedetomidine (Dexmed group, $\mathrm{N}=43$ ) or $8 \mathrm{mg}$ dexamethasone (Dexa group, $\mathrm{N}=43$ ) after induction of anesthesia and just before skin incision. Randomization was based on computer-generated codes maintained in sequentially numbered opaque envelopes. We did not include a placebo control group because this would be unethical, as the patients were at risk of developing PONV according to Apfel's risk score [6].

Anesthesia management was performed similarly for both groups using a standard protocol. Patients were pre-medicated with IV midazolam (1-3 mg) in the preoperative holding area. Prophylactic antibiotic in the form of $1 \mathrm{~g}$ cefazolin sodium IV was given 30 min before induction. Patients were then transferred to the operating room (OR). Standard physiologic monitoring included electrocardiograph leads II \& V, heart rate, arterial oxygen saturation $\left(\mathrm{SpO}_{2}\right)$ measured by pulse oximeter, noninvasive blood pressure, and end-tidal $\mathrm{CO}_{2}\left(\mathrm{ETCO}_{2}\right)$. After preoxygenation, anesthesia was induced with IV fentanyl $1 \mu \mathrm{g} / \mathrm{kg}$ and propofol $2-2.5 \mathrm{mg} / \mathrm{kg}$, followed by IV rocuronium bromide $0.6 \mathrm{mg} / \mathrm{kg}$ to facilitate endotracheal intubation. The lungs were ventilated with a fraction of inspired oxygen $\left(\mathrm{FIO}_{2}\right)$ of 0.5 using a mixture of oxygen and air with volume-controlled ventilation. Patients were ventilated with a tidal volume $\left(\mathrm{V}_{\mathrm{T}}\right)$ of $6-8 \mathrm{ml} / \mathrm{kg}$, respiratory rate $(\mathrm{RR})$ of $10-12$ breaths/min, and inspiratoryto-expiratory ratio of $1: 2$. Ventilatory parameters $\left(V_{T}, R R\right)$ were adjusted to maintain $\mathrm{ETCO}_{2}$ tension around $35 \mathrm{mmHg}$. A forced-air warming system was used to maintain temperature above $36.0^{\circ} \mathrm{C}$ using a Bair-Hugger warmer (Arizant Medical, Eden Prairie, MN, USA).

Anesthesia was maintained with $1.0-2.5 \%$ end-tidal concentration sevoflurane in $50 \%$ oxygen and $50 \%$ air. Rocuronium boluses were given to maintain $1 / 4$ to $2 / 4$ twitches of train-of-four (Dräger, Trident NMT monitor, Telford, PA, USA). Fentanyl boluses and sevoflurane concentrations were adjusted to maintain the depth of anesthesia between 40 and 60 by using COVIDIEN BIS LoC 2 Channel (Dräger Medical GmbH, Lübeck, Germany). An orogastric tube was inserted orally (through another endotracheal tube inserted esophageally using Glidescope) after induction of anesthesia to deflate the stomach and was suctioned and removed just before extubation. During anesthesia, all patients received IV lactated Ringer's solution at a rate of $10 \mathrm{ml} / \mathrm{kg}$. They were maintained on $2 \mathrm{ml} / \mathrm{kg} / \mathrm{h}$ during recovery until they were able to tolerate oral fluids. The study drug was diluted to a total of $100 \mathrm{ml} \mathrm{0.9 \%}$ sodium chloride and infused over a $15 \mathrm{~min}$ period. For dexmedetomidine, $2 \mathrm{ml}$ of the drug (Precedex ${ }^{\circledR}$, Hospira Inc., Lake Forest, IL, USA) was withdrawn and added to 98 $\mathrm{ml}$ of $0.9 \%$ sodium chloride injection to a total of $100 \mathrm{ml}$. After mixing well, the final concentration was $2 \mu \mathrm{g} / \mathrm{ml}$. The doses were calculated and prepared by anesthesiologists who were not involved in the study. Data were collected by anesthesiologists who were blinded to the study drug.

All patients were put in a standard reverse Trendelenburg position (rT) during surgery with head up $30^{\circ}$ and left lateral tilt $15^{\circ}$ (the right side of the OR table was elevated $15^{\circ}$ ). Pneumoperitoneum was established with $\mathrm{CO}_{2}$, and the intra-abdominal pressure was maintained at $12 \mathrm{mmHg}$. Laparoscopic cholecystectomy was performed under video guidance with four punctures of the abdomen. After gas deflation, all patients received $1 \mathrm{~g}$ paracetamol infusion over $15 \mathrm{~min}$. In addition, $10 \mathrm{ml}$ of $0.5 \%$ bupivacaine were injected locally at the four punctures of the abdomen for postoperative pain. Upon completion of surgery, atropine and neostigmine (1/2.5 mg) were given slowly IV to 
restart spontaneous breathing, which was followed by tracheal extubation. Patients were sent to the recovery room and later to the ward.

During the preoperative visit, all patients were familiarized with a visual analogue scale (VAS) of 0-100 $\mathrm{mm}$ for PONV [7]. On this scale, a score of 0 meant no nausea, while a score of 100 meant the worst imaginable nausea. Occurrence of vomiting or retching was scored as 100 . Nausea was defined as a subjectively unpleasant sensation associated with awareness of the urge to vomit, while retching was defined as making an effort to vomit without expulsion of gastric contents, and vomiting was defined as the forceful expulsion of even a small amount of upper gastrointestinal contents through the mouth [8]. During the first 24 $\mathrm{h}$ postoperatively, the total number of patients who had nausea and/or vomiting was calculated. If patients experienced nausea $\geq 60$ on a $100 \mathrm{~mm}$ VAS, and/or retching or vomiting, or requested an antiemetic, a rescue antiemetic consisting of ondansetron $4 \mathrm{mg}$ was given slowly intravenously. At $24 \mathrm{~h}$ postoperatively, patients were asked to rate their nausea throughout the study period on a $100 \mathrm{~mm}$ VAS.

Also, pain severity was assessed using a $100 \mathrm{~mm}$ VAS, on which 0 indicated no pain and 100 indicated the worst pain imaginable. As postoperative pain after laparoscopic cholecystectomy has been reported to be more intense during the first 4 $\mathrm{h}$ [9], we measured the pain score at the following intervals: on arrival in the PACU (T0) and hourly for the next $10 \mathrm{~h}$ (T1-T10). The Ramsay Sedation Score was used to assess sedation hourly during the $6 \mathrm{~h}$ after arrival in the PACU [10]. During the $24 \mathrm{~h}$ after surgery, tramadol 50-100 $\mathrm{mg}$ was given IV if the pain score was $\geq 40 \mathrm{~mm}$ on a $100 \mathrm{~mm}$ VAS. The total amounts of tramadol and ondansetron given during the $24 \mathrm{~h}$ after surgery were calculated for both study groups. Mean arterial blood pressure and heart rate were recorded at the following time points: $T_{0}$ : just before giving study medication; $\mathrm{T}_{1}: 5 \mathrm{~min}$ after study medication; $\mathrm{T}_{2}: 30$ min after study medication; $\mathrm{T}_{3}: 5$ min after extubation; $\mathrm{T}_{4}$ : on arrival at the PACU; and then hourly for the next $6 \mathrm{~h}\left(\mathrm{~T}_{5-10}\right)$.

\section{Data management}

Study variables and data were coded and entered into a spreadsheet using the Statistical Package for Social Sciences (SPSS) version 17.0 (SPSS Inc., Chicago, IL, USA). Descriptive data analysis was performed, and outcomes were compared between the two study groups and presented in the form of mean and standard deviation or number and percent. Chi-square and Student's t-test were used to assess significant differences in categorical and continuous variables, respectively.

Sample size was calculated based on the hypothesis that dexmedetomidine would detect a minimal difference of $50 \%$ and dexamethasone would detect a difference of $22 \%$. The marginal error was set at $\mathrm{P}<0.05$, and the power of the study at $80 \%$. Sample size (n) was calculated according to the following equation [11].

$$
\mathrm{n}=\frac{\left(\mathrm{z}_{\alpha / 2}+\mathrm{z}_{\beta}\right)^{2}\left[\left(\mathrm{r} \theta_{1}\left(1-\theta_{1}\right)+\theta_{2}\left(1-\theta_{2}\right)\right]\right.}{\left(\theta_{1}-\theta_{2}\right)^{2}}=43
$$

Where $\alpha=$ the probability of type I error (significance level) (the probability of rejecting a true null hypothesis) $=0.05, \beta=$ the probability of type II error = the probability of failing to reject a false null hypothesis $=(1-0.8)=0.2, \theta_{1}=$ the true mean response rate of dexmedetomidine $=50 \%=0.5, \theta_{2}=$ the true mean response rate of the control, dexamethasone $=22 \%=0.22$

The value of $\mathrm{r}=$ allocation ratio for Dexmed $\left(\mathrm{n}_{1}\right)$ to Dexa $\left(\mathrm{n}_{2}\right)$ groups $=1, \mathrm{z}=1.96$

$\theta_{1}-\theta_{2}=$ the difference between the true mean response rates of group 1 (test drug $\left.\left[\theta_{1}\right]\right)$ and group 2 (control $\left[\theta_{2}\right]$ ).

\section{Results}

Table 1 shows the baseline characteristics for both study groups. There was no statistically significant difference between the two groups in age, gender, weight, ASA status, smoking, history of motion sickness, history of previous PONV, and duration of

Table 1. Characteristics of the Study Population

\begin{tabular}{lccc}
\hline \multicolumn{1}{c}{ Variable } & $\begin{array}{c}\text { Dexmed } \\
\text { group } \\
(\mathrm{N}=43)\end{array}$ & $\begin{array}{c}\text { Dexa } \\
\text { group } \\
(\mathrm{N}=43)\end{array}$ & P value \\
\hline Continuous & & & \\
Age (yr) & $31.1 \pm 2.4$ & $32.3 \pm 2.1$ & 0.7 \\
Weight (kg) & $69.4 \pm 2.2$ & $71.5 \pm 3.1$ & 0.8 \\
Duration of anesthesia (min) & $93.5 \pm 15.3$ & $95.9 \pm 10.6$ & 0.8 \\
$\quad$ Duration of surgery (min) & $75.7 \pm 13.9$ & $72.8 \pm 16.4$ & 0.9 \\
Categorical & & & \\
Gender & & & \\
$\quad$ M & $9(21 \%)$ & $6(14 \%)$ & 0.4 \\
$\quad$ F & $34(79 \%)$ & $37(86 \%)$ & \\
ASA status & $33(77 \%)$ & $34(79 \%)$ & 0.7 \\
$\quad$ I & $10(23 \%)$ & $9(21 \%)$ & \\
$\quad$ II & & & \\
Smokers & $7(16 \%)$ & $5(12 \%)$ & 0.5 \\
$\quad$ Yes & $36(84 \%)$ & $38(88 \%)$ & \\
$\quad$ No & & & \\
History of motion sickness & $6(14 \%)$ & $3(7 \%)$ & 0.3 \\
$\quad$ Yes & $37(86 \%)$ & $40(97 \%)$ & \\
$\quad$ No & & & \\
History of previous PONV & $3(7 \%)$ & $4(9 \%)$ & 0.6 \\
$\quad$ Yes & $40(93 \%)$ & $39(91 \%)$ & \\
No &
\end{tabular}

Values are mean \pm SD or number of patient (percentage). No significant differences $(\mathrm{P}>0.05)$ between the two groups in age, gender, weight, ASA status, smoking, history of motion sickness, history of previous postoperative nausea and/or vomiting (PONV), and duration of surgery or duration of anesthesia. 
Table 2. Number of Patients Who Experienced PONV within 24-h Postoperatively

\begin{tabular}{|c|c|c|c|c|c|}
\hline Variable & $\begin{array}{l}\text { Dexmed group } \\
\quad(\mathrm{N}=43)\end{array}$ & $\begin{array}{l}\text { Dexa group } \\
(\mathrm{N}=43)\end{array}$ & $\mathrm{RR}$ & $95 \%$ CI & $\mathrm{P}$ value \\
\hline \multicolumn{6}{|l|}{ Nausea } \\
\hline Yes & $5(11.6 \%)$ & 7 (16.3\%) & 0.7 & $0.24-2.05$ & 0.5 \\
\hline No & $38(88.4 \%)$ & $36(83.7 \%)$ & & & \\
\hline \multicolumn{6}{|l|}{ Retching } \\
\hline Yes & $2(4.7 \%)$ & $2(4.7 \%)$ & 1 & $0.14-6.77$ & 1.0 \\
\hline No & $41(95.3 \%)$ & $41(95.3 \%)$ & & & \\
\hline \multicolumn{6}{|l|}{ Vomiting } \\
\hline Yes & $2(4.7 \%)$ & $3(7.0 \%)$ & 0.66 & $0.11-3.89$ & 0.6 \\
\hline No & $41(95.3 \%)$ & 40 (93\%) & & & \\
\hline \multicolumn{6}{|c|}{ Overall PONV } \\
\hline Yes & $9(20.9 \%)$ & $12(27.9 \%)$ & 0.7 & $0.35-1.59$ & 0.4 \\
\hline No & $34(79 \%)$ & $31(72 \%)$ & & & \\
\hline
\end{tabular}

Values are number of patient (percentage). RR: Relative risk, CI: Confidence interval. No significant differences $(\mathrm{P}>0.05)$ between study groups regarding postoperative nausea, retching, vomiting or overall postoperative nausea and/or vomiting (PONV).

Table 3. Comparison of Severity of PONV and Intraoperative \& Postoperative Medications

\begin{tabular}{lccccc}
\hline \multicolumn{1}{c}{ Variable $($ Mean $\pm \mathrm{SD})$} & $\begin{array}{c}\text { Dexmed group } \\
(\mathrm{N}=43)\end{array}$ & $\begin{array}{c}\text { Dexa group } \\
(\mathrm{N}=43)\end{array}$ & $\begin{array}{c}\text { Mean of } \\
\text { difference }\end{array}$ & 95\% CI & P value \\
\hline Severity of PONV (VAS) & $55 \pm 29$ & $65 \pm 22$ & -10 & -21.04 to 1.04 & 0.07 \\
Ondansetron dose during 24 h (mg) & $0.93 \pm 0.15$ & $1.03 \pm 0.33$ & -0.1000 & -0.2099 to 0.0099 & 0.07 \\
Tramadol dose during 24 $\mathrm{h}(\mathrm{mg})$ & $85 \pm 5$ & $110 \pm 12$ & -25 & -28.94 to -21.06 & $<0.0001$ \\
Intra-operative fentanyl $(\mu \mathrm{g})$ & $95 \pm 11$ & $115 \pm 18$ & -20 & -26.40 to -13.60 & $<0.0001$ \\
First analgesic request $(\mathrm{min})$ & $97 \pm 31$ & $83 \pm 21$ & 14 & 2.64 to 25.36 & 0.0163
\end{tabular}

Values are mean \pm SD. CI: Confidence interval. No significant differences $(\mathrm{P}>0.05)$ between study groups in the severity of postoperative nausea and/ or vomiting $(\mathrm{PONV})$ or ondansetron consumption during the first $24 \mathrm{~h}$. There were significant differences $(\mathrm{P}<0.05)$ between study groups regarding the mean total amount of intra-operative fentanyl and postoperative tramadol consumption. The first analgesic request was significantly delayed in the Dexmed group compared to the Dexa group $(\mathrm{P}=0.02)$.

surgery or anesthesia. The incidence of PONV was $20.9 \%$ ( 9 patients) in the dexmedetomidine group compared to $27.9 \%$ (12 patients) in the dexamethasone group $(\mathrm{P}=0.4)$ (Table 2). Also, Table 2 shows that neither nausea nor vomiting or retching was significant. The severity of PONV assessed by VAS was less in the Dexmed group compared to the Dexa group, but it did not reach statistical significance $(P=0.07)$ (Table 3). Also, fewer patients in the Dexmed group required an antiemetic compared to the Dexa group (16.3 vs. 23.3\%; respectively), but the difference did not reach statistical significance $(P=0.5)$. The mean total amount of intra-operative fentanyl was significantly lower in the Dexmed group $(\mathrm{P}<0.0001)$ (Table 3$)$. Within the first $24 \mathrm{~h}$ postoperatively, the mean total amount of tramadol consumption was significantly lower in the Dexmed group $(\mathrm{P}<0.0001)$ (Table $3)$. However, there was no significant difference in the mean total amount of ondansetron between the two groups (Table 3). When the VAS was used to assess pain, the severity of pain was significantly lower in the Dexmed group during the $4 \mathrm{~h}$ assessment after arrival in the PACU compared to the Dexa group (Fig. 1). The first analgesic request was significantly delayed in the Dexmed

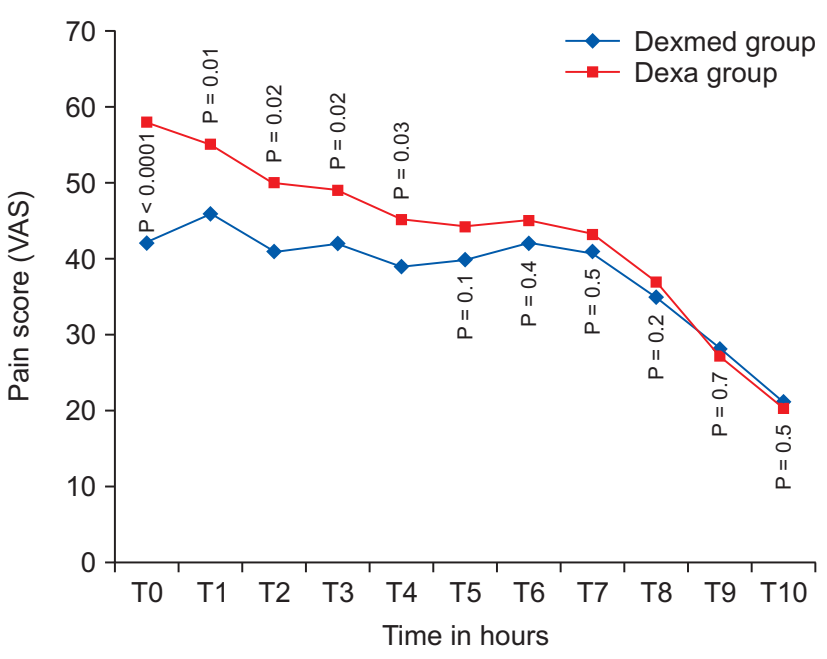

Fig. 1. Comparison of postoperative visual analogue scale (VAS) of pain between both groups. T0: on arrival at post-anesthesia care unit (PACU), (T1-T10): hourly for the next $10 \mathrm{~h}$. The severity of pain was significantly lower $(\mathrm{P}<0.05)$ in the Dexmed group on arrival at PACU and during the first 4-h assessment after arrival at the PACU compared to the Dexa group. No significant changes occurred after that $(\mathrm{P}>0.05)$. 


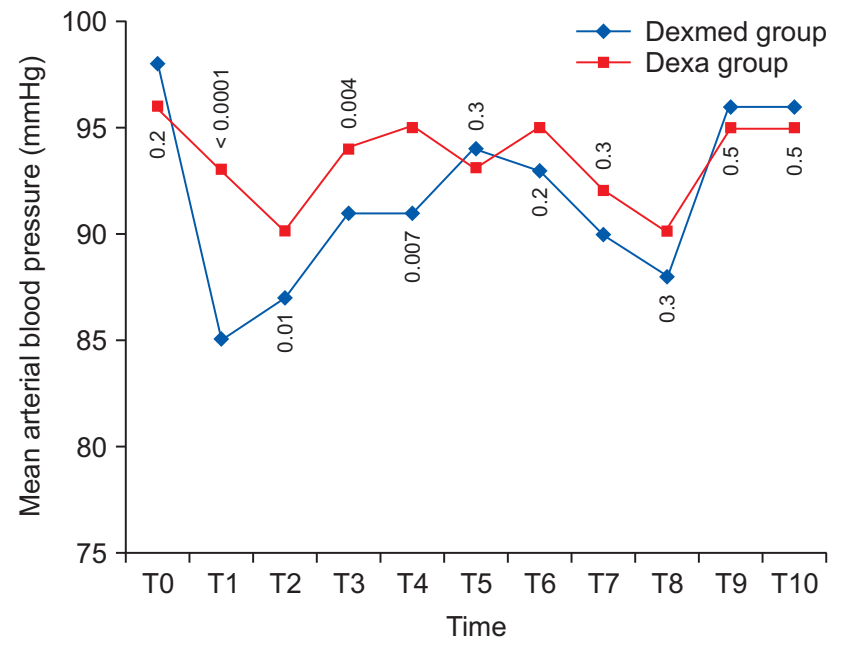

Fig. 2. Perioperative changes in mean arterial blood pressure in both groups. T0: just before giving study medication; T1: 5 min after study medication; T2: 30 min after study medication; T3: 5 min after extubation; T4: on arrival at the PACU; and then hourly for the next $6 \mathrm{~h}$ (T5-10). The mean arterial blood pressure was significantly lower $(\mathrm{P}<0.05)$ in the Dexmed group after administration of dexmedetomidine till arrival at post-anesthesia care unit, but no significant changes occurred after that $(\mathrm{P}>0.05)$.

group compared to the Dexa group $(\mathrm{P}=0.02)$ (Table 3). During the $6 \mathrm{~h}$ after arrival in PACU, the mean Ramsey Sedation Score was significantly higher in the Dexmed group $(4.2 \pm 0.8)$ compared to the Dexa group $(2.7 \pm 0.9)$, with $\mathrm{P}<0.0001$. However, all patients in both groups were arousable and responded to oral commands in the PACU and in the ward.

The mean arterial blood pressure and heart rate were significantly lower in the Dexmed group after administration of dexmedetomidine and on arrival at the PACU, but no significant changes occurred after that (Figs. 2 and 3). However, after administration of study medication during anesthesia, ephedrine $(10 \mathrm{mg}$ ) was required to treat hypotension in one patient in the Dexmed group compared with none in the dexamethasone group. Otherwise, the differences were not clinically significant. None of patients in either group were given atropine to treat bradycardia during anesthesia. In the post-anesthesia recovery unit, none of the patients needed ephedrine or atropine.

\section{Discussion}

The present study showed that dexmedetomidine reduces the incidence and severity of PONV similar to dexamethasone. During the first $24 \mathrm{~h}$ after laparoscopic cholecystectomy, it decreases early postoperative pain severity and reduces analgesic consumption. Our finding is consistent with Massad et al. [12], who found that dexmedetomidine reduced the incidence of PONV in female patients undergoing elective diagnostic

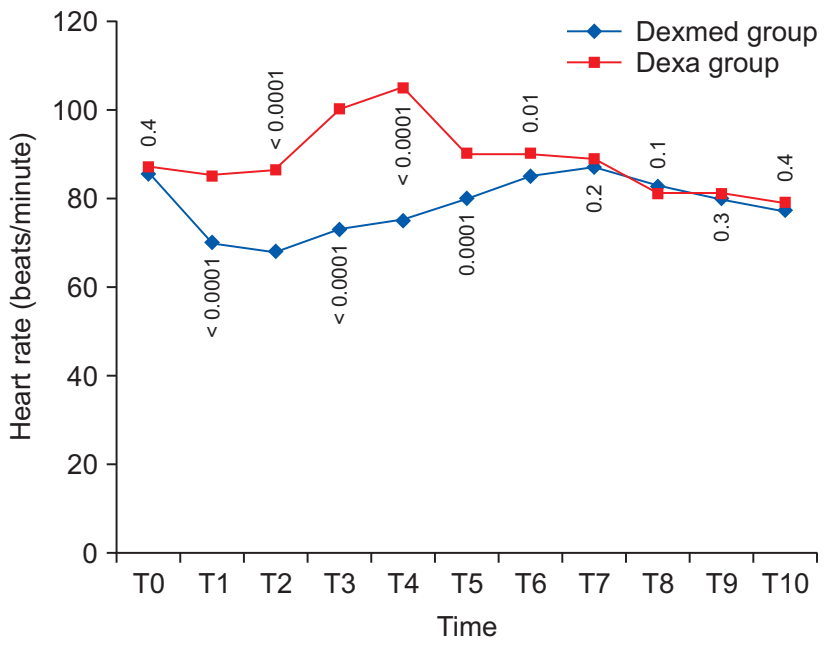

Fig. 3. Perioperative changes in heart rate in both groups. T0: just before giving study medication; T1: 5 min after study medication; T2: 30 min after study medication; T3: 5 min after extubation; T4: on arrival at post-anesthesia care unit (PACU); and then hourly for the next $6 \mathrm{~h}(\mathrm{~T} 5-10)$. The heart rate was significantly lower $(\mathrm{P}<0.05)$ in the Dexmed group after administration of dexmedetomidine till $2 \mathrm{~h}$ after arrival at PACU, but no significant changes occurred after that $(\mathrm{P}>0.05)$.

laparoscopic gynecological procedures. They attributed their observation to the decrease in the overall consumption of anesthetic medications. In patients undergoing uvulo-palatopharyngoplasty, Abdelmageed et al. [13] reported that PONV was significantly reduced in the dexmedetomidine group during the first $24 \mathrm{~h}$ postoperatively. They attributed their finding to the reduction of postoperative morphine consumption in the dexmedetomidine group. Moreover, Goksu et al. [14] used dexmedetomidine for sedation during functional endoscopic sinus surgery under local anesthesia and reported a significantly lower incidence of PONV in the dexmedetomidine group, compared to a placebo group, without adverse effects. After giving a single dose of $0.5 \mu \mathrm{g} / \mathrm{kg}$ dexmedetomidine administered at the end of the surgery in female patients undergoing breast cancer surgery, Kim et al. [15] found that the overall incidence of PONV during the $24 \mathrm{~h}$ after surgery showed a trend toward a lower incidence in the dexmedetomidine group, but it did not reach statistical significance. However, they reported that dexmedetomidine significantly reduced the incidence of severe PONV during the first $24 \mathrm{~h}$ after surgery. Furthermore, they found that dexmedetomidine improved the quality of recovery (QoR-40), and reduced the rescue analgesic requirements during the first $24 \mathrm{~h}$ after surgery without prolonging recovery times or causing serious hemodynamic side effects. Their dose $(0.5 \mu \mathrm{g} / \mathrm{kg})$ may not have been sufficient to reach statistical significance in the prevention of PONV; that is why a dose of $1 \mu \mathrm{g} / \mathrm{kg}$ was used in our study. In their systematic review and meta-analysis, Blaudszun et al. 
[16] concluded that perioperative systemic administration of a2-agonists decreases postoperative opioid consumption, pain severity, and nausea without delaying recovery times.

Possible explanations for the lower incidence of PONV in the dexmedetomidine group may be related to the reduced consumption of intra-operative and postoperative opioids and inhaled anesthetics [17]. Also, dexmedetomidine decreases noradrenergic activity as a result of binding to alpha- 2 presynaptic inhibitory adreno-receptors in the locus coeruleus, which may result in an antiemetic effect [18]. Lastly, it may be related to the overall reduction in sympathetic outflow and catecholamine release caused by dexmedetomidine. High sympathetic tone and catecholamine release may trigger PONV [8].

The dexmedetomidine-induced opioid-sparing effect observed in the present study has also been documented by other investigators. Gurbet et al. [17] reported that patients who received dexmedetomidine required a lower cumulative amount of morphine during the first $48 \mathrm{~h}$ after total abdominal hysterectomy in spite of similar pain scores in the two studied groups. Also, Arain et al. [19] compared intra-operative dexmedetomidine to morphine sulfate in patients undergoing elective inpatient surgery and found that both groups had similar pain scores. However, the morphine group required $66 \%$ more morphine to achieve the same analgesic effect as the dexmedetomidine group. The reduction of postoperative pain by dexmedetomidine could be explained by the activation of the $\alpha_{2}$-adrenoreceptor in the dorsal horn of the spinal cord, which inhibits the release of substance $\mathrm{P}$, which modulates the transmission of nociceptive signals in the central nervous system, leading to reduction of nociceptive inputs during the acute postoperative period [20].

Contrary to our results, Lee et al. [21] reported that the incidence of PONV did not differ between a general anesthesia group who did not receive dexmedetomidine and a monitored anesthetic care group who received dexmedetomidine for closed reduction of nasal bone fracture. However, their dexmedeto- midine group had their surgery under local anesthesia and was compared to a general anesthesia group. In addition, they assessed the PONV only in the PACU. The study by Shin et al. [22] found no significant difference between dexmedetomidine and control groups in the incidence of PONV, despite decreasing anesthetic consumption and maintenance of stable hemodynamics in the Dexmed group. However, the difference in the incidence of PONV between their study and our work may be related to the timing of dexmedetomidine dose (pre-anesthesia), type of surgery (gynecological), and sample size (only 21 patients in each group). Also, most importantly, they observed PONV only in the recovery room.

In the present study, we found that the incidence of PONV in the Dexa group was $27.9 \%$. This finding is similar to previous reports $[2,23,24]$ of use of dexamethasone as a prophylactic against PONV after laparoscopic cholecystectomy. The exact mechanism of the antiemetic action of dexamethasone is not well known. Elhakim et al. [25] suggested that dexamethasone might act as a serotonin receptor antagonist in the gastrointestinal tract. Others [26] proposed that dexamethasone might lead to a reduction in parasympathetic impulses to the brain by decreasing tissue inflammation around the surgery site.

Based on this study finding, dexmedetomidine has an effect similar to that of dexamethasone in reducing the incidence and severity of PONV. In addition, dexmedetomidine is superior to dexamethasone in reducing postoperative pain and total analgesic consumption during the first $24 \mathrm{~h}$ after laparoscopic cholecystectomy, without any major adverse effects. Further studies are needed to determine the optimum dose and timing of administration of dexmedetomidine to prevent PONV without effects on patient hemodynamics or sedation. We therefore conclude that a single dose of dexmedetomidine is appropriate for preventing PONV in patients undergoing laparoscopic cholecystectomy.

\section{References}

1. Apfel CC, Korttila K, Abdalla M, Kerger H, Turan A, Vedder I, et al. A factorial trial of six interventions for the prevention of postoperative nausea and vomiting. N Engl J Med 2004; 350: 2441-51.

2. Wang JJ, Ho ST, Liu YH, Lee SC, Liu YC, Liao YC, et al. Dexamethasone reduces nausea and vomiting after laparoscopic cholecystectomy. Br J Anaesth 1999; 83: 772-5.

3. Gupta N, Rath GP, Prabhakar H, Dash HH. Effect of intraoperative dexmedetomidine on postoperative recovery profile of children undergoing surgery for spinal dysraphism. J Neurosurg Anesthesiol 2013; 25: 271-8.

4. Aho M, Lehtinen AM, Erkola O, Kallio A, Korttila K. The effect of intravenously administered dexmedetomidine on perioperative hemodynamics and isoflurane requirements in patients undergoing abdominal hysterectomy. Anesthesiology 1991; 74: 997-1002.

5. Lawrence CJ, De Lange S. Effects of a single pre-operative dexmedetomidine dose on isoflurane requirements and perioperative hemodynamic stability. Anesthesia 1997; 52: 736-44.

6. Apfel CC, Läärä E, Koivuranta M, Greim CA, Roewer N. A simplified risk score for predicting postoperative nausea and vomiting: conclusions from cross-validations between two centers. Anesthesiology 1999; 91: 693-700. 
7. Ali SZ, Taguchi A, Holtmann B, Kurz A. Effect of supplemental pre-operative fluid on postoperative nausea and vomiting. Anaesthesia 2003; 58: 780-4.

8. Watcha MF, White PF. Postoperative nausea and vomiting: its etiology, treatment, and prevention. Anesthesiology 1992; 77: 162-84.

9. Fredman B, Jedeikin R, Olsfanger D, Flor P, Gruzman A. Residual pneumoperitoneum: a cause of postoperative pain after laparoscopic cholecystectomy. Anesth Analg 1994; 79: 152-4.

10. Ramsey MA, Savage TM, Simpson BR, Goodwin R. Controlled sedation with alphaxalone-alphadolone. Br Med J 1974; 2: 656-9.

11. Casagrande JT, Pike MC. An improved approximate formula for calculating sample sizes for comparing two binomial distributions. Biometrics 1978; 34: 483-6.

12. Massad IM, Mohsen WA, Basha AS, Al-Zaben KR, Al-Mustafa MM, Alghanem SM. A balanced anesthesia with dexmedetomidine decreases postoperative nausea and vomiting after laparoscopic surgery. Saudi Med J 2009; 30: 1537-41.

13. Abdelmageed WM, Elquesny KM, Shabana RI, Abushama HM, Nassar AM. Analgesic properties of a dexmedetomidine infusion after uvulopalatopharyngoplasty in patients with obstructive sleep apnea. Saudi J Anaesth 2011; 5: 150-6.

14. Goksu S, Arik H, Demiryurek S, Mumbuc S, Oner U, Demiryurek AT. Effects of dexmedetomidine infusion in patients undergoing functional endoscopic sinus surgery under local anaesthesia. Eur J Anaesthesiol 2008; 25: 22-8.

15. Kim SH, Oh YJ, Park BW, Sim J, Choi YS. Effects of single-dose dexmedetomidine on the quality of recovery after modified radical mastectomy: a randomized controlled trial. Minerva Anestesiol 2013; 79: 1248-58.

16. Blaudszun G, Lysakowski C, Elia N, Tramèr MR. Effect of perioperative systemic $a 2$ agonists on postoperative morphine consumption and pain intensity: systematic review and meta-analysis of randomized controlled trials. Anesthesiology 2012; 116: 1312-22.

17. Gurbet A, Basagan-Mogol E, Turker G, Ugun F, Kaya FN, Ozcan B. Intraoperative infusion of dexmedetomidine reduces perioperative analgesic requirements. Can J Anaesth 2006; 53: 646-52.

18. Whittington RA, Virág L. Dexmedetomidine-induced decreases in accumbal dopamine in the rat are partly mediated via the locus ceruleus. Anesth Analg 2006; 102: 448-55.

19. Arain SR, Ruehlow RM, Uhrich TD, Ebert TJ. The efficacy of dexmedetomidine versus morphine for postoperative analgesia after major inpatient surgery. Anesth Analg 2004; 98: 153-8.

20. Jain G, Bansal P, Ahmad B, Singh DK, Yadav G. Effect of the perioperative infusion of dexmedetomidine on chronic pain after breast surgery. Indian J Palliat Care 2012; 18: 45-51.

21. Lee K, Yoo BH, Yon JH, Kim KM, Kim MC, Lee WY, et al. General anesthesia versus monitored anesthetic care with dexmedetomidine for closed reduction of nasal bone fracture. Korean J Anesthesiol 2013; 65: 209-14.

22. Shin HW, Yoo HN, Kim DH, Lee H, Shin HJ, Lee HW. Preanesthetic dexmedetomidine $1 \mu \mathrm{g} / \mathrm{kg}$ single infusion is a simple, easy, and economic adjuvant for general anesthesia. Korean J Anesthesiol 2013; 65: 114-20.

23. Feo CV, Sortini D, Ragazzi R, De Palma M, Liboni A. Randomized clinical trial of the effect of preoperative dexamethasone on nausea and vomiting after laparoscopic cholecystectomy. Br J Surg 2006; 93: 295-9.

24. Erhan Y, Erhan E, Aydede H, Yumus O, Yentur A. Ondansetron, granisetron, and dexamethasone compared for the prevention of postoperative nausea and vomiting in patients undergoing laparoscopic cholecystectomy: A randomized placebo-controlled study. Surg Endosc 2008; 22: 1487-92.

25. Elhakim M, Nafie M, Mahmoud K, Atef A. Dexamethasone $8 \mathrm{mg}$ in combination with ondansetron $4 \mathrm{mg}$ appears to be the optimal dose for the prevention of nausea and vomiting after laparoscopic cholecystectomy. Can J Anaesth 2002; 49: 922-6.

26. Wang JJ, Ho ST, Uen YH, Lin MT, Chen KT, Huang JC, et al. Small dose dexamethasone reduces nausea and vomiting after laparoscopic cholecystectomy: a comparison of tropisetron with saline. Anesth Analg 2002; 95: 229-32. 